\title{
Selectivity of Canary HVC Neurons for the Bird's Own Song: Modulation by Photoperiodic Conditions
}

\author{
Catherine Del Negro, Katia Lehongre, and Jean-Marc Edeline \\ Laboratoire de Neurobiologie de l'Apprentissage, de la Mémoire, et de la Communication, Unité Mixte de Recherche 8620, Université Paris-Sud, 91405 \\ Orsay, France
}

To what extent seasonal factors modify the neuronal functional properties within the nuclei of the avian song system remains an open question. In adult songbirds, neurons of the song premotor nucleus HVC (used as a proper name) exhibit selective responses for the bird's own song (BOS). Here we examine whether, outside the breeding season, when songs are less stereotyped, HVC neurons of male canaries still respond selectively to the BOS produced during this period. In an initial experiment, single-unit recordings $(n=114)$ revealed that the neuronal selectivity for the current BOS was attenuated in males exposed to a short-day photoperiod (typical of the nonbreeding season) compared with that found in males exposed to a long-day photoperiod. In long-day conditions, $35 \%$ of the cells responded to the BOS, whereas only $12 \%$ did in short-day conditions; there were four times more selective cells $\left(d^{\prime}>1\right)$ in long-day than in short-day conditions.

To determine whether these effects were the consequence of differences in acoustic features between breeding and nonbreeding songs, neurons $(n=72)$ recorded in short-day conditions were tested with both a short-day BOS and a long-day BOS. A low percentage of neurons exhibited responses to short-day or to long-day BOS (11\% for each song). Responses of putative interneurons (spike duration $<0.4 \mathrm{~ms}$ ) and of putative relay cells were similarly attenuated by the short-day conditions. These results strongly suggest that, in canary, rather than being a fixed property, the selectivity for the BOS moves along a continuum and peaks when the day length mimics the breeding conditions.

Key words: songbirds; in vivo recordings; seasonal plasticity; auditory selectivity; electrophysiology; HVC nucleus

\section{Introduction}

Seasonal changes in the brain of songbirds are one of the most famous examples of naturally occurring plasticity that have been described in any vertebrate species. In males of temperate-zone songbird species, the volume, spacing, and replacement of constituent neurons of several telencephalic nuclei that control song behavior change significantly across seasons (Nottebohm 1981; Nottebohm et al., 1986) (for review, see Alvarez-Buylla and Kirn 1997; Tramontin and Brenowitz, 2000). Anatomical investigations have revealed morphological modifications in the song nuclei such as changes in (1) the size of neuronal somata, (2) the complexity of dendritic arbors, and (3) the number of spines and synapses (DeVoogd and Nottebohm, 1981; DeVoogd et al., 1985; Hill and DeVoogd, 1991). Logically, these anatomical alterations should dramatically impact the functional networks within and between song nuclei and potentially should have important consequences on neuronal properties. Surprisingly, although one can suspect that neuronal responsiveness within the song nuclei

Received Aug. 3, 2004; revised April 1, 2005; accepted April 8, 2005.

This work was supported by the Action Concertée Incitative "Neurosciences Integratives et Computationnelles" from the French Research Ministry. We thank Gérard Dutrieux for help with computer programming, Pascale Veyrac and Nathalie Samson for animal care, and three anonymous reviewers for their helpful comments.

Correspondence should be addressed to Dr. Jean-Marc Edeline, Neurobiologie de l'Apprentissage, de la Mémoire et de la Communication, Unité Mixte de Recherche Centre National de la Recherche Scientifique 8620, Université Paris-Sud, Batiment 446, 91405 Orsay, France. E-mail: jean-marc.edeline@ibaic.u-psud.fr.

DOI:10.1523/JNEUROSCI.4847-04.2005

Copyright $\odot 2005$ Society for Neuroscience $\quad$ 0270-6474/05/254952-12\$15.00/0 varies across seasons, no study has ever attempted to document whether such changes indeed occur.

For more than 20 years, many studies have described that HVC (used here as a proper name) neurons of anesthetized songbirds show highly selective responses, firing more to playback of the bird's own song (BOS) than to reverse BOS or other conspecific songs (Margoliash, 1983; Lewicki and Konishi, 1995; Theunissen and Doupe, 1998; Mooney, 2000) [for a reevaluation of this property in awake birds, see Cardin and Schmidt (2003)]. Thus far, song-selective neurons have been studied either in nonseasonal breeding birds such as the zebra finch (Margoliash and Fortune, 1992) or in fully reproductive seasonal birds (Margoliash, 1983, 1986; Mooney et al., 2001), leaving unclear whether HVC neurons remain selective outside the breeding season. At least two distinct outcomes can be expected when comparing this selectivity across seasons. An initial possibility is that the selectivity is only expressed at the breeding season, potentially as a consequence of particularly strong synaptic connections between and/or within structures. In this case, selectivity should be attenuated outside the breeding season. However, HVC neurons are also involved in song production by generating premotor activity during singing (Yu and Margoliash, 1996; Hahnloser et al., 2002). If one suspects that the selectivity of HVC neurons for the BOS relies, at least partly, on auditory-motor interactions (through auditory feedback), it should be maintained outside the breeding season in the case of birds singing in all seasons. 
The present study compared the auditory selectivity of HVC neurons for the BOS in canaries housed in breeding and nonbreeding conditions. An initial experiment revealed that the selectivity for a current BOS is reduced in males exposed to a shortday photoperiod compared with that found in males exposed to a long-day photoperiod. To interpret unambiguously these results, it was crucial to distinguish between two explanations: (1) either the selectivity of HVC neurons indeed changes with seasons or (2) the less stereotyped short-day song is not efficient in driving HVC neurons, but HVC responses remain unchanged to the long-day song. In a second experiment, single units recorded in the HVC of canaries kept on short days were tested with both a long-day BOS and a short-day BOS produced by the same birds.

\section{Materials and Methods}

\section{Subjects}

Twenty-eight singing adult male canaries (Serinus canaria) were used for this experiment (national authorization to conduct animal research number 006692). All canaries, born in the Laboratory of Ethology and Cognition (University of Paris X, Nanterre, France), were chosen from a pool of 1- to 3-year-old birds that had previous sexual experience. They belonged to an outbreed form of the common canary with a heterogeneous genetic background.

Before the electrophysiological investigations, birds were maintained for at least 4 weeks either under a long-day photoperiod ("spring-like" $15 / 9 \mathrm{~h} \mathrm{light/dark} \mathrm{cycle,} \mathrm{long-day} \mathrm{birds} \mathrm{in} \mathrm{experiment} 1$ ) or under a shortday photoperiod ("autumn-like" 9/15 h light/dark cycle; short-day birds in experiment 1; all birds in experiment 2). Initially, the long-day birds were kept on the short-day photoperiod for at least 4 months, and, conversely, the short-day birds were initially kept on the long-day photoperiod for the same amount of time, before a progressive shift in the photoperiod. Under these laboratory conditions, exposure to the photostimulatory lighting regimen ( $15 / 9 \mathrm{~h}$ light/dark cycle) is well known to stimulate reproductive behaviors in male as in female (Storey and Nicholls, 1976; Appeltants et al., 2001; Del Negro and Edeline, 2001; Parisot et al., 2002). When canaries were shifted from a long-day photoperiod to a short-day one, we observed that most of them did not sing for 2-4 weeks. Nottebohm et al. (1986) reported previously that some canaries did not sing for a few weeks during the summer-fall period. In the present study, when short-day canaries started to produce unstable songs, there was an inter-individual variability similar to that observed in long-day conditions: some birds sung intensively, whereas others sung less frequently.

In experiment 1 , males were exposed either to a long-day photoperiod $(n=9)$ or to a short-day one $(n=9)$. In experiment 2 , all males $(n=10)$ were housed on short-day photoperiod.

\section{Song recordings and analysis}

In experiment 1 , each cell was tested with three stimuli: a current BOS (recorded from the photoperiod under which the bird was housed), this BOS played in reverse, and a conspecific song of a domesticated canary (DC1) (Del Negro and Edeline, 2001). In experiment 2, each cell was tested with five stimuli: a short-day BOS and a long-day BOS, presented either normally or time reversed, and the same conspecific song DC1. The long-day BOS was recorded during the previous breeding season.

For each bird, songs were recorded once per day on 1-3 d, when photoperiod had been changed for at least 4 weeks. The bird was placed in a sound attenuation chamber equipped with a Marantz (Osnabrück, Germany) PMD 201 recorder and a Sennheiser (Wedemark, Germany) microphone. Recorded songs were digitized with SoundEdit16 software (22 kHz sampling rate; Macromedia, San Francisco, CA) and stored on a hard disk for analysis.

Canary songs consisted of a series of phrases; each phrase is composed of a syllable repeated multiple times (see examples in Fig. $1 A-C$ ). A syllable is formed of one to five elements; an element appears in a sound spectrogram as an uninterrupted separate trace. A series of phrases had to be at least $2.0 \mathrm{~s}$ long to be considered as a song, and two songs had to be separated at least by a silence period of $0.4 \mathrm{~s}$ long. Song quantification was performed on a spectrogram with special focus on measuring song length, phrase length, and silence between two successive phrases. Because male canaries use a large syllable repertoire, analyses of longduration samples (at least $150 \mathrm{~s}$ of song, pauses excluded) of individual songs were required to determine the syllable repertoire (Güttinger et al., 1985). Identifying different syllable types was straightforward: in spectrograms, syllables differ in shapes and in duration. The composition of syllable repertoire differed between individuals and also changed with the photoperiod conditions (Nottebohm et al., 1986, 1987). In experiment 2, because individual songs were recorded during both photoperiod conditions, it was possible to determine changes in the composition of syllable repertoire between long-day songs (first recorded) and short-day songs. We quantified the percentage of new syllable types that appeared in the short-day repertoire. The number of fast-frequency modulated syllable types ( $>40 \mathrm{~Hz}$ over $1 \mathrm{~ms}$ ) was counted because it can exhibit changes with the seasonal conditions in wild canaries (Leitner et al., 2001).

Previous studies in domesticated canaries reported that stereotypy of syllables showed seasonal changes (Güttinger, 1985; Nottebohm et al., 1986, 1987). At the breeding season, syllables are produced in a strikingly uniform manner, whereas in autumnal songs, the shape of syllables differs within phrases (Fig. $1 B$ ). The stability of song was quantified by the number of variations of syllable shape per second of song. This was calculated by subtracting the total number of phrases from the total number of variations of syllable shape, divided by the total song duration. Syllables were considered to be the same when they had the same frequency modulation on the spectrogram and similar frequency bandwidth (within $0.25 \mathrm{kHz}$ ). Automatic analyses were performed using Avisoft software (Avisoft Bioacoustics, Berlin, Germany). A syllable exhibiting on average more than two variations was considered unstable. For each bird, the proportion of unstable syllable types and that of unstable song were calculated.

The selection of the song stimuli used as the BOS was made by identifying the most representative song in the bird's repertoire (Fig. 1C). This selection was possible because, for each bird, sets of syllable types occurred in almost each song (both in breeding and in nonbreeding conditions), whereas other syllable types occurred rarely. To determine the syllable types that frequently recurred, each syllable type was labeled, and the percentage of occurrence of each label was calculated by dividing the number of occurrences of this label by the cumulative number of phrases over the song sample. For each song, the cumulative percentage of occurrence was calculated without taking into account repetitions. Songs composed of frequently occurring syllable types obtained the highest cumulative percentages. As illustrated in Figure $1 C$, the frequently produced syllable types occurred very often in the same order and formed somewhat fixed sequences. The song selected as the BOS contained the highest number of frequently occurring sequences.

In the two experiments, the same conspecific song (DC1) was presented. This song, produced by a male exposed to long days in the Laboratory of Ethology and Cognition was used previously in both behavioral and electrophysiological experiments (Nagle and Kreutzer, 1997; Del Negro and Edeline, 2001). It contains a particular song phrase that elicits (1) a high level of sexual responses in females and (2) changes in call rate in males (Vallet and Kreutzer, 1995; Parisot et al., 2002). The experimental birds never heard this DC1 song before the recording session.

During electrophysiological investigations, each song was followed by $8 \mathrm{~s}$ of silence (intertrial interval) and was repeated at least 10 times. Song stimuli were presented randomly.

\section{Experimental protocol and electrophysiological recording procedure}

Recent studies reported that HVC neuronal responses to BOS playback are quite variable in undrugged birds. For example, responses obtained during waking were found to be strongly decreased compared with those obtained in slow-wave sleep (Nick and Konishi, 2001). During waking, responses to BOS can be dramatically changed from time to time and can even totally disappear at arousal from sleep (Cardin and Schmidt, 2003). For all of these reasons, it was important to assess seasonal changes in 
HVC reactivity by recording cells under anesthesia, a state in which every study performed thus far has found that HVC neurons of reproductive birds respond selectively to BOS playback.

Animals were anesthetized by an initial injection of urethane ( $1.5 \mathrm{~g} / \mathrm{kg}$, i.m.) supplemented as needed to maintain an areflexive state. Surgery and electrophysiological investigations were made in an acoustically isolated chamber (model chamber AC2; IAC, New York, NY). Anesthetized canaries were immobilized in a stereotaxic holder that allowed their heads to be tilted at $45^{\circ}$, according to the brain atlas (Stokes et al., 1974). The speaker, delivering the song stimuli, was placed as close as possible from the entrance of a hollow ear bar.

During each session, extracellular recordings were obtained first with high-impedance tungsten electrodes $(10-12 \mathrm{M} \Omega)$ to ascertain the location of HVC on the basis of physiological criteria, such as highly irregular discharges of spontaneous activity. No search stimuli were used while lowering the electrode. Subsequent recordings were collected with glass pipettes (5-15 M $\Omega$ ) filled with $3 \mathrm{~m} \mathrm{NaCl}$. The signal coming from the electrode was amplified (gain 5000 ; bandpass, $0.3-10 \mathrm{kHz}$ ) and sent in parallel to an audio monitor and to a voltage discriminator (model 74-60-1; Frederic Haer Company, Bowdoinham, ME). The single-unit waveform and the corresponding pulses generated by the discriminator were displayed on a digital oscilloscope, digitized ( $50 \mathrm{kHz}$ sampling rate), and stored on the hard disk. The transistor-transistor logic pulses generated by the voltage window discriminator were also sent to the acquisition board (PClab, PCL 720) of a Pentium II computer, which provided the time of occurrence of pulses corresponding to each action potential with a resolution of $50 \mu \mathrm{s}$.

\section{Data analysis}

Song-evoked neuronal responses. During off-line analyses, peristimulus time histograms ( $25 \mathrm{~ms}$ bin) were built with 10 repetitions of each stimulus. ANOVAs were conducted (Statview 5.0; Abacus Concepts, Calabasas, CA) to determine whether songs caused changes in firing rate. Evoked responses were analyzed by comparing the firing rate obtained during the entire song duration with spontaneous firing rate obtained during a 2 s period preceding the song. Potentially, by quantifying only the firing rate, we might have underestimated the number of cells responding to the different songs (Cardin and Schmidt 2003; Huetz et al., 2004). However, there is no reason to suspect that this underestimation differed between long-day and shortday conditions.

For each song stimulus, the number of neurons exhibiting a significant increase in activity in response to song playback was quantified (paired $t$ test; $p<0.05$ level). Because (1) the spontaneous firing rate of HVC cells strongly differed between cell types and (2) this rate differed between short-day and long-day conditions, $Z$-scores were used to quantify and compare response strength to song stimuli
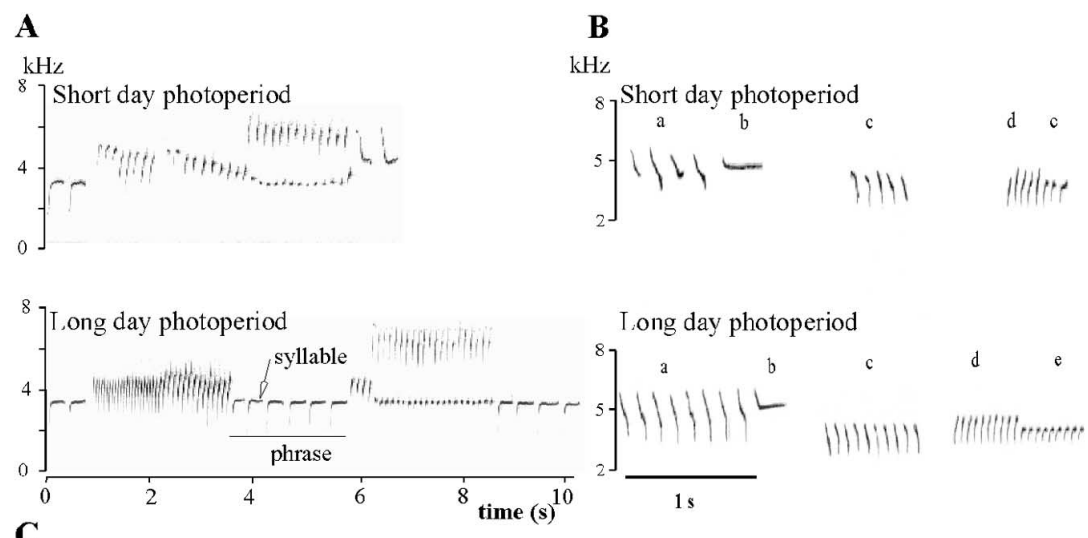

C
\begin{tabular}{|c|c|c|c|c|c|c|c|c|c|c|c|c|c|c|c|c|c|c|c|c|}
\hline song number & 1 & 2 & 3 & 4 & 5 & 6 & 7 & 8 & 9 & 10 & 11 & 12 & 13 & 14 & 15 & 16 & 17 & 18 & 19 & 20 \\
\hline sum of \% & 63 & 71 & 78 & 55 & 64 & 44 & 67 & 62 & 68 & 69 & 67 & 77 & 44 & 74 & 71 & 42 & 76 & 70 & 79 & 67 \\
\hline
\end{tabular}

\begin{tabular}{|c|c|c|c|c|c|c|c|c|c|c|c|c|c|c|c|c|c|c|c|c|}
\hline sum of \% & 63 & 71 & 78 & 55 & 64 & 44 & 67 & 62 & 68 & 69 & 67 & 77 & 44 & 74 & 71 & 42 & 76 & 70 & 79 & 67 \\
\hline
\end{tabular}

C1

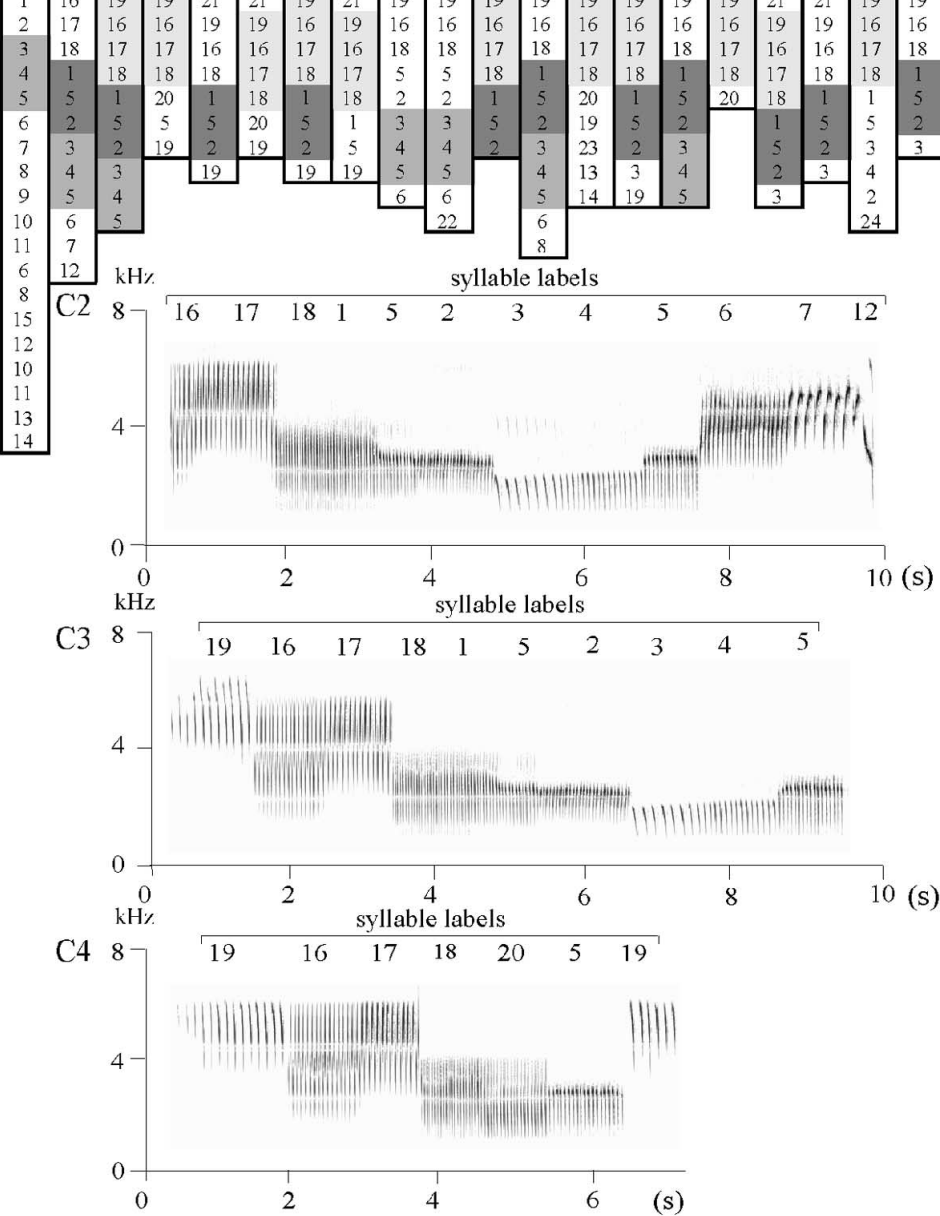

Figure 1. Song characteristics in long-day and short-day conditions. A, Two songs from the same bird recorded during shortday and long-day conditions. Note that the phrases composing the long-day song are longer than those composing the short-day song. $\boldsymbol{B}$, Difference in syllable stability between long-day and short-day photoperiod. Sonograms show five examples of phrases $(\boldsymbol{a}-\boldsymbol{e})$ found in both long-day and short-day songs from the same bird. Note that syllables produced under long-day conditions were repeated with a high degree of stereotypy, whereas syllables produced under short-day conditions were variable in their shape. The first syllable type (a) produced under short-day conditions exhibited four variations in its shape. $\boldsymbol{C}$, Selection of the song used as the BOS. To determine how the different syllable types are ordered within songs from a given bird, each syllable type was labeled with a number. The table (C1) shows the succession of different syllable types within 20 songs of the same bird. For each syllable type, the percentage of times it occurred was calculated. The cumulative percentage obtained for each of the 20 songs is indicated in the second line of the table. The song selected as the BOS (number 3 here) was composed of nine different syllable types (1 syllable type is repeated twice, syllable 5). The percentage of occurrence of these nine syllables was: $16,10,7,7,5,13,10$, 6 , and 4\%, respectively. The sum of these percentages was $78 \%$. Within the 20 songs, the sequences $19-16-17-18,1-5-2,3-4-5$ (labeled using a gray scale) were present 11,11 , and 7 times, respectively. The song selected as the BOS contained these three sequences. $\mathbf{C 2}-\mathbf{C}$, The song selected as the BOS (C3) is presented above those produced immediately before (C2) and after (C4) it (songs 2-3-4 of the table). In C2-C4, the numbers above each phrase refer to those of the table (C1). 


\begin{tabular}{|c|c|c|c|c|c|c|}
\hline & \multicolumn{3}{|l|}{ Experiment 1} & \multicolumn{3}{|c|}{ Experiment $2(n=10)$} \\
\hline & $\begin{array}{l}\text { Long-day } \\
\text { birds }(n=9)\end{array}$ & $\begin{array}{l}\text { Short-day } \\
\text { birds }(n=9)\end{array}$ & $\begin{array}{l}\text { Unpaired } \\
t \text { test }\end{array}$ & $\begin{array}{l}\text { Long-day } \\
\text { songs }\end{array}$ & $\begin{array}{l}\text { Short-day } \\
\text { songs }\end{array}$ & $\begin{array}{l}\text { Paired } \\
t \text { test }\end{array}$ \\
\hline \multicolumn{7}{|l|}{ Temporal parameters } \\
\hline Mean song duration & $9.8 \pm 1.5$ & $7.0 \pm 1.0$ & $p=0.14$ & $8.9 \pm 1.2$ & $5.9 \pm 1.1$ & $p=0.036$ \\
\hline Mean phrase duration & $1.13 \pm 0.14$ & $0.75 \pm 0.6$ & $p=0.02$ & $0.94 \pm 0.04$ & $0.71 \pm 0.04$ & $p<0.002$ \\
\hline Mean interval duration & $0.050 \pm 0.004$ & $0.072 \pm 0.004$ & $p=0.002$ & $0.060 \pm 0.007$ & $0.08 \pm 0.01$ & $p=0.012$ \\
\hline \multicolumn{7}{|l|}{ Syllable repertoire } \\
\hline Repertoire size & $19.8 \pm 3.3$ & $23.9 \pm 3.7$ & $p=0.42$ & $24.1 \pm 1.8$ & $28.3 \pm 4.0$ & $p=0.2$ \\
\hline Number of syllable types composed of rapid frequency modulation & $8.6 \pm 1.6$ & $9.8 \pm 1.8$ & $p=0.62$ & $9.8 \pm 2.1$ & $9.0 \pm 1.5$ & $p=0.6$ \\
\hline \multicolumn{7}{|l|}{ Syllable stability } \\
\hline Number of variations per second & $0.95 \pm 0.17$ & $2.25 \pm 0.21$ & $p<0.001$ & $0.67 \pm 0.09$ & $2.8 \pm 0.3$ & $p<0.001$ \\
\hline$\%$ of unstable syllable & $32.97 \pm 5.2$ & $63.45 \pm 4.12$ & $p=0.024$ & $24.5 \pm 3.8$ & $60.4 \pm 4.9$ & $p<0.001$ \\
\hline$\%$ of unstable song & $37.78 \pm 6.70$ & $67.67 \pm 4.87$ & $p<0.001$ & $23.9 \pm 4.3$ & $71.1 \pm 3.7$ & $p<0.001$ \\
\hline
\end{tabular}

(Theunissen and Doupe, 1998; Mooney, 2000). The Z-score was classically defined by the following formula:

$$
Z=\frac{\bar{S}_{F R}-B_{F R}}{\sqrt{\operatorname{Var}\left(S_{\mathrm{FR}}\right)+\operatorname{Var}\left(B_{\mathrm{FR}}\right)-2 \operatorname{Covar}\left(S_{\mathrm{FR}}, B_{\mathrm{FR}}\right)}},
$$

where $S_{\mathrm{FR}}$ is the mean firing rate during the stimulus, $B_{\mathrm{FR}}$ is the mean firing rate during the baseline period, and the denominator is the SD of $S_{\mathrm{FR}}-B_{\mathrm{FR}}$. Mean $Z$-scores were compared using either paired $t$ tests for within-group comparisons or unpaired $t$ tests for between-group comparisons.

The selectivity of a given neuron for forward over reverse BOS playback (or over the conspecific song DC1) was measured using the psychophysical metric $d^{\prime}$ (Green and Swets, 1966), because it estimates the discriminability between two stimuli (Solis and Doupe, 1997; Theunissen and Doupe, 1998; Janata and Margoliash, 1999; Mooney, 2000). The $d^{\prime}$ value comparing the response to the BOS relative to reverse BOS is given by the following:

$$
d^{\prime}=\frac{2\left(R_{\mathrm{FR}_{\mathrm{BOS}}}-R_{\mathrm{FR}}\right)}{\sqrt{\sigma^{2} \mathrm{BOS}+\sigma^{2} \mathrm{REV}}},
$$

where $R$ is the difference between the firing rate during stimulus presentation and that during the $2 \mathrm{~s}$ baseline period before stimulus presentation; $\sigma^{2}$ is its variance. The more positive is $d^{\prime}$, the more song selective is the response of a neuron. A $d^{\prime}$ value $>1.0$ was used as the criterion for identifying a cell as "selective" (Theunissen and Doupe, 1998; Janata and Margoliash, 1999).

Cell-type determination based on action potential waveforms. As in previous in vivo intracellular and extracellular studies (Mooney, 2000; Mooney et al., 2001; Hahnloser et al., 2002; Rauske et al., 2003), we distinguished putative HVC relay cells and putative HVC interneurons based on the spike waveform of the recorded cells. Classically, the spike amplitude is defined as the voltage difference between the peak of the negativity and the peak of the positivity that follows it; the spike width is the duration between the beginning of the negativity and the peak of the following positive wave (Wilson et al., 1994; Gur et al., 1999; Henze et al., 2000; Del Negro and Edeline, 2002). Spike parameters were always analyzed blind to the photoperiod conditions of the bird and blind to the responses obtained during the experiment. These parameters, as well as the spontaneous firing rate, were compared between the different conditions (season and cell type) using unpaired $t$ test. Analyzing the spike waveform from a large number of HVC neurons $(n=374)$, the distribution of spike duration significantly differed from a normal one: two subpopulations of cells, one exhibiting thin spikes $(<0.4 \mathrm{~ms})$ and the other exhibiting broad spike ( $\geq 0.45 \mathrm{~ms}$ ), were found (Del Negro and Edeline, 2002). Therefore, cells were assigned to these two categories, thin or broad, using a cutoff criterion of $0.4 \mathrm{~ms}$. Because recent studies reported that relay cells and interneurons exhibit different auditory responses (phasic vs tonic) to song stimuli (Mooney, 2000; Mooney et al., 2001), particular attention was devoted to obtain a similar proportion of thin spike cells in long-day males as well as in short-day males in both experiments.

\section{Results}

Manipulations of photoperiod markedly affected the gonadal status of birds. In experiment 1, testes of males exposed to long days were much heavier than those of males exposed to short days (mean \pm SEM, $0.198 \pm 0.012$ vs $0.059 \pm 0.020 \mathrm{~g} ; t_{(16)}=5.44 ; p<$ $0.001)$. In experiment 2 , all short-day males had regressed testes $(0.042 \pm 0.026 \mathrm{~g})$.

\section{Song characteristics in long-day and short-day photoperiod} Day length affected several temporal parameters of song (Table 1). Duration of both songs and phrases were shorter in short-day than in long-day songs, whereas silent intervals between phrases were longer (see example in Fig. 1A). The composition of the syllable repertoire also changed with the photoperiod conditions. When birds were switched from long-day to short-day conditions, $44 \%$ (range, $8-63 \%$ ) of the short-day repertoire was composed of new syllable types. Despite the production of new syllable types, the total number of syllable types did not differ between long-day and short-day songs, in both experiment 1 and experiment 2 (Table 1). Also, the number of syllable types composed of fast-frequency modulated elements $(>40 \mathrm{~Hz}$ in $1 \mathrm{~ms})$ did not differ between long-day and short-day songs in both experiments. As illustrated in Figure $1 B$, syllables produced in shortday conditions had less stereotyped shape than those produced in long-day conditions. The number of variations in syllable shape per second, the proportion of unstable syllable in individual syllable repertoire, and that of unstable song were significantly higher in short-day than in long-day songs (Table 1).

Songs selected as the BOS were composed of $8-10$ syllable types that occurred frequently. The cumulative percentage of these syllable types was, respectively, $57.5 \pm 7.0$ and $61.8 \pm 6.6 \%$ for the long-day and short-day BOS in experiment 1 and $74.0 \pm$ 3.3 and $64.6 \pm 4.7 \%$ for those in experiment 2 . As illustrated in Figure $1 C$, the frequently produced syllables occurred very often in the same order and formed fixed sequences. In both long-day and short-day conditions, the song selected as the BOS contained the highest number of such frequently occurring sequences.

\section{Experiment 1: selectivity to a current BOS in long-day and short-day males}

To assess responses to forward BOS, reverse BOS, and a conspecific song DC1, 55 neurons were recorded in long-day canaries $(n=9)$ and 59 neurons in short-day canaries $(n=9)$. Electrode 
Table 2. Day length conditions affected both auditory responsiveness and song selectivity of neurons recorded in the HVC

\begin{tabular}{|c|c|c|c|c|c|c|c|c|}
\hline & \multicolumn{3}{|c|}{ Number of cells exhibiting a significant response to } & \multicolumn{4}{|c|}{ Number of cells exhibiting a significant response to } & \multirow{2}{*}{$\begin{array}{l}\text { Number of cells } \\
\text { with a } d^{\prime}>1 \\
(\text { selective cells })^{a}\end{array}$} \\
\hline & Forward BOS & Reverse BOS & DC1 & 0 stimulus & 1 stimulus & 2 stimuli & 3 stimuli & \\
\hline \multicolumn{9}{|l|}{ Long-day males } \\
\hline$(n=55)$ & 19 & 4 & 2 & $33(60 \%)$ & $19(35 \%)^{b}$ & $3(5 \%)$ & $0(0 \%)$ & 12 of $22(55 \%)$ \\
\hline \multicolumn{9}{|l|}{ Short-day males } \\
\hline$(n=59)$ & 7 & 6 & 7 & $46(78 \%)$ & $7(12 \%)^{c}$ & $5(8 \%)$ & $1(2 \%)$ & 2 of $13(15 \%)$ \\
\hline
\end{tabular}

${ }^{a}$ These numbers included only cells with significant responses to at least one song stimulus.

${ }^{b}$ Of these 19 cells, 16 responded to forward BOS.

'Of these seven cells, two responded to forward BOS.

impedance did not differ between longday and short-day males ( 6.8 vs $6.6 \mathrm{M} \Omega$; $t_{(93)}<1$; NS). Thirty-one cells were recorded with tungsten electrodes; the other 83 cells were recorded with glass pipettes. The proportion of cells recorded with tungsten electrodes did not differ between long-day and short-day males ( 25 vs $28 \%$; $\chi^{2}<1$; NS). Three to 10 cells were recorded from each animal $(6.6 \pm 1.0$ in long-day males; $6.5 \pm 0.8$ in short-day males). One to four cells were obtained at each electrode penetration, and we used one to four sites of electrode penetration for each animal (3.4 \pm 0.4 in long-day males; $2.8 \pm 0.2$ in short-day males).

In long-day males, the evoked firing rate during forward BOS was significantly higher than the spontaneous rate (2.9 vs 2.1 spikes $\left./ \mathrm{s} ; t_{(54)}=2.78 ; p=0.007\right)$. In response to reverse BOS, there was no significant increase in firing rate (2.4 vs 2.1 spike/s; $\left.t_{(54)}=1.3 ; p=0.19\right)$. Also, the conspecific song DC1 did not evoke a change in firing rate (2.3 vs 2.1 spike/s; $t_{(54)}=1.26 ; p=0.21$ ). In short-day males, spontaneous activity was lower than that of neurons recorded in long-day males $\left(1.1\right.$ vs 2.1 spikes/s; $t_{(112)}=2.85 ; p=$ 0.005). On average, neither the forward BOS nor the reverse BOS nor the conspecific song DC1 elicited increase in firing rate above spontaneous activity (BOS, 1.0 vs 1.4 spike/s, $t_{(58)}=1.52, p=0.13$; reverse BOS, 1.0 vs 1.1 spike $/ \mathrm{s}, t_{(58)}=1.37, p=0.17$; DC1, 1.0 vs 1.0 spike/s, $t_{(58)}<1$, NS).

Beside these group data, statistical analyses revealed proportions of auditory responsive neurons, i.e., neurons exhibiting a significant song-evoked response, in long-day and in short-day conditions (Table 2). Three results emerged from examination of this table. First, the number of responsive neurons was higher in longday males than in short-day ones ( 22 of 55 vs 13 of $59 ; \chi^{2}=4.32$; $p=0.037)$. Second, the distribution of the number of cells responding to each song (forward BOS, reverse BOS, or DC1) differed between the two conditions $\left(\chi^{2}=8.26 ; p=0.016\right)$. Third, the distribution of the number of cells responding to zero, one, two, or three stimuli also differed between the two conditions $\left(\chi^{2}\right.$ $=9.05 ; p=0.02)$. These results indicated that, in long-day males,
Long-day males
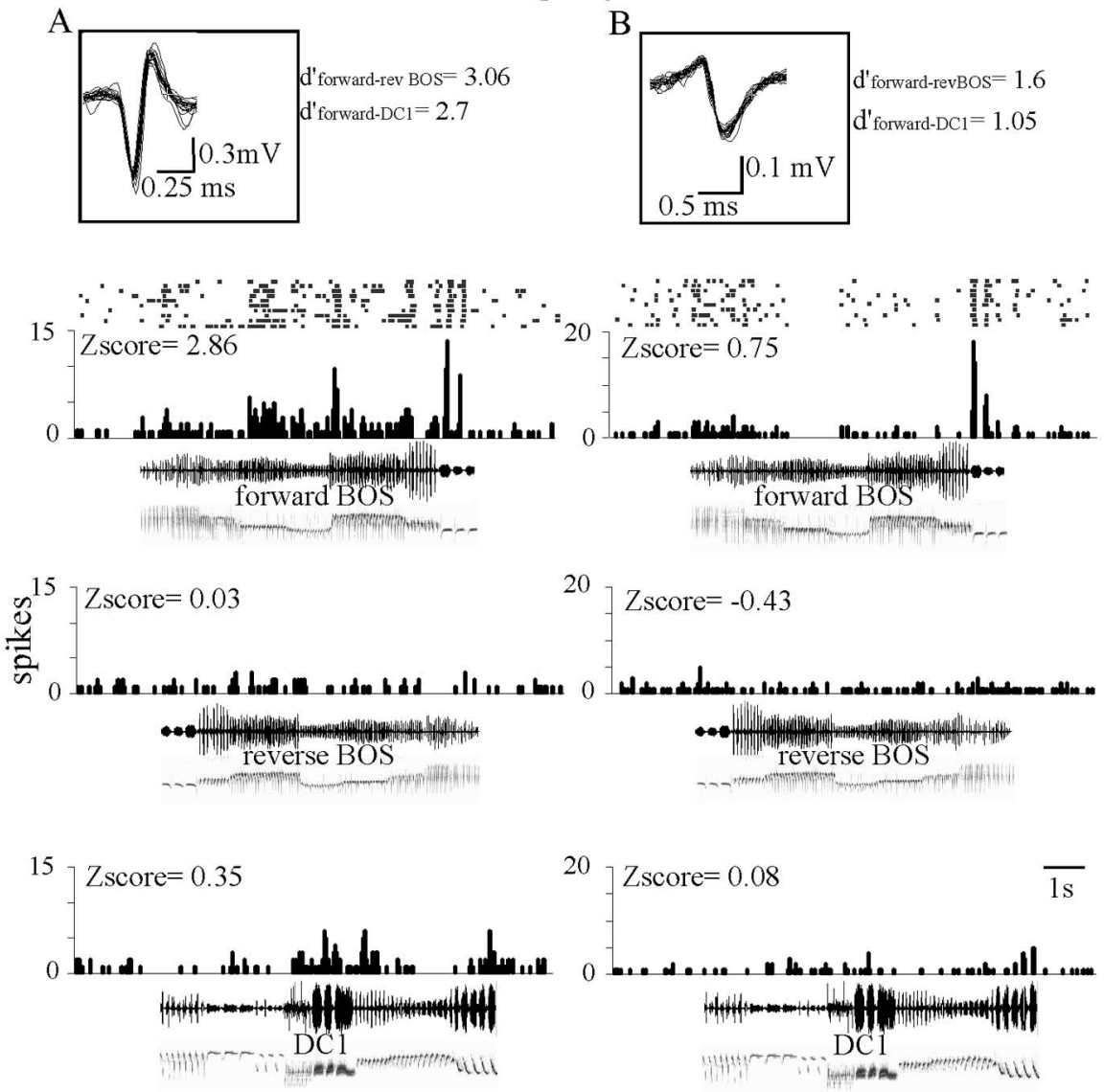

Figure 2. Two examples of song-selective HVC neurons in a long-day male. A, During the playback of forward BOS, this cell exhibited distinct phasic peaks superimposed on a tonic response. In contrast, reverse BOS playback elicited no change in firing rate. This neuron displayed a thin action potential (duration, $0.25 \mathrm{~ms}$ ). The inset shows its action potential waveform ( 30 sweeps, $50 \mathrm{kHz}$ sampling rate), composed of an abrupt negative peak followed by a positive one, typical of thin spike waveform. $\boldsymbol{B}$, This neuron exhibited a phasic increase in activity to forward BOS playback. In contrast, phasic responses were absent during both reverse BOS and DC 1 playbacks. This neuron displayed a broad action potential (duration, $0.45 \mathrm{~ms}$ ). The inset shows its waveform (30 sweeps, $50 \mathrm{kHz}$ sampling rate). These two neurons were recorded from two different penetrations in the HVC of a long-day male. Histograms display the number of action potentials per bins of $25 \mathrm{~ms}$ and are accompanied by raster plots for forward BOS responses. Oscillograms and sonograms of songs are below histograms. The Z-score values are indicated above histograms. Song selectivity values $\left(d^{\prime}\right)$ for forward over reverse BOS and for forward BOS over conspecific song DC1 are indicated next to the action potential waveform. The selected long-day BOS was composed of eight different syllable types. The percentage of occurrence of each of them over all the collected songs was $5,4,4,12,6,11,14$, and $14 \%$, respectively. The sum of these percentages was $70 \%$. most of the auditory responsive neurons responded only to one song stimulus, the forward BOS (see two examples in Fig. 2), whereas in short-day males, half of the auditory responsive neurons responded to, at least, two song stimuli (see an example in Fig. 3).

We used $Z$-scores to compare responses between short-day and long-day males (Fig. 4A). A repeated ANOVA on $Z$-scores 


\section{Short-day male}
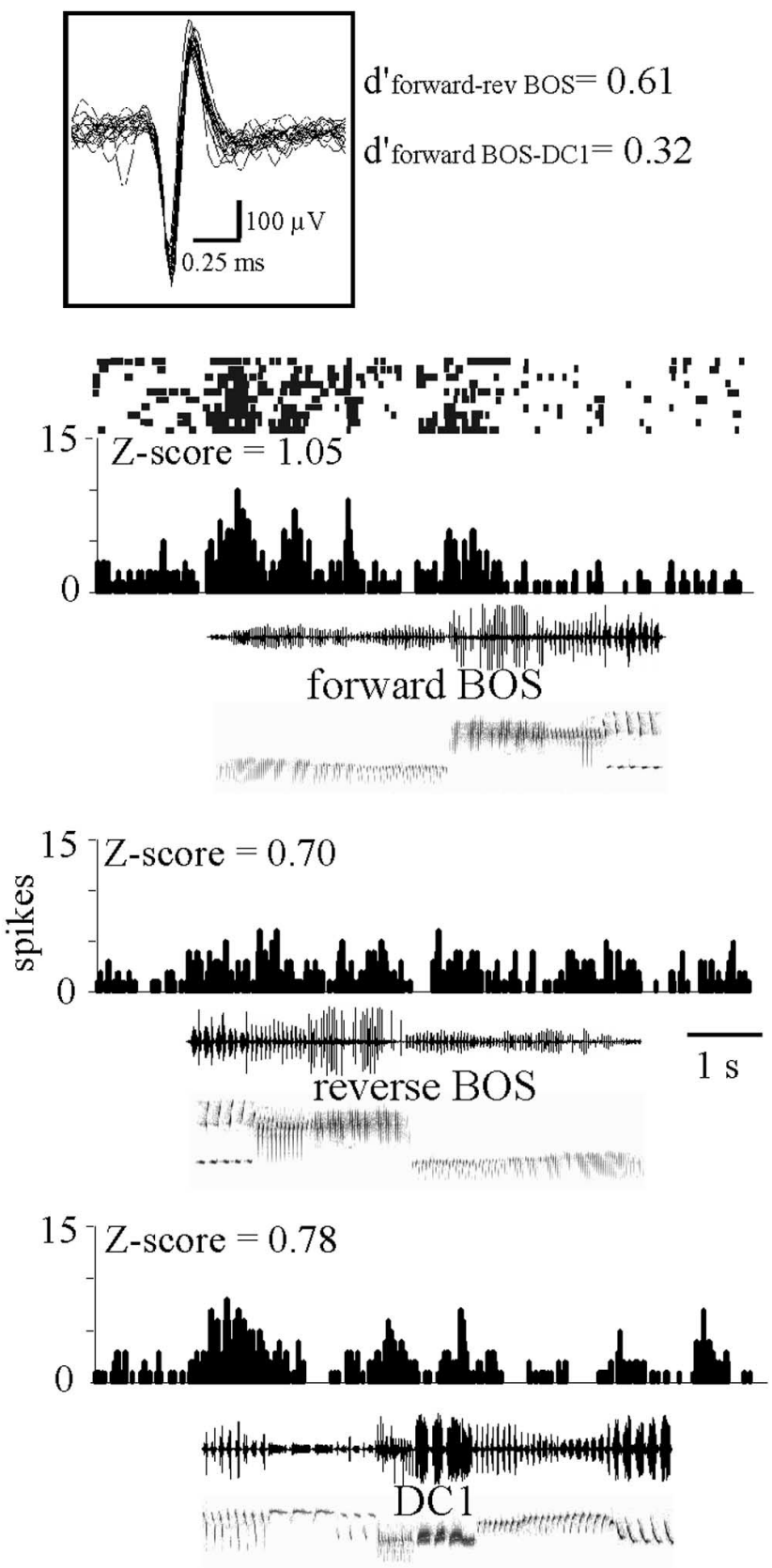

Figure 3. Example of a nonselective HVC neuron in a short-day male. This cell exhibited a tonic increase in activity in response to playbacks of the three song stimuli: the forward and reverse version of the current BOS and the conspecific song DC1. The inset shows its action potential waveform (30 sweeps, $50 \mathrm{kHz}$ sampling rate). This neuron displayed a thin action potential (duration, $0.3 \mathrm{~ms}$ ). Histograms display the number of action potentials per bins of 25 ms and are accompanied by raster plots for forward BOS responses. Oscillograms and sonograms of songs are below histograms. The Z-score values are indicated above histograms. Song selectivity values $\left(d^{\prime}\right)$ for forward over reverse BOS and for forward BOS over conspecific song DC1 are indicated next to the action potential waveform. The selected long-day BOS was composed of seven different syllable types. The percentage of occurrence of each of them over all the collected songs was $7,12,6,9,11,7$, and $7 \%$, respectively. The sum of these percentages was $61 \%$.

(song and photoperiod as factors) revealed a significant effect of the song factor $\left(F_{(2,112)}=6.66\right.$; $\left.p=0.002\right)$, no effect of the photoperiod factor $(F<1$; NS) and a significant interaction between the two factors $\left(F_{(2,112)}=11.96 ; p<0.001\right)$. In long-day males,
A. Experiment 1

Long-day vs. short-day males

B. Experiment 2

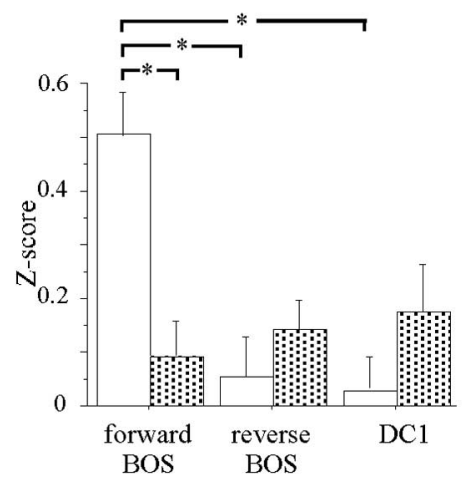

Short-day males

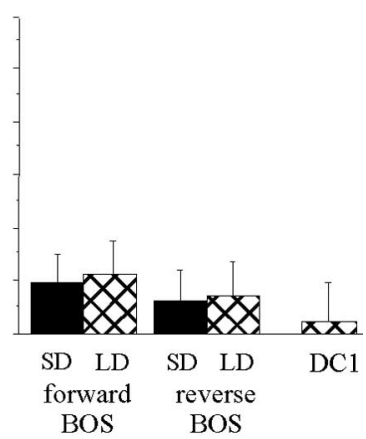

Figure 4. Differences in response to song playbacks are only found in long-day conditions. A, Results of experiment 1: comparisons of responses to song stimuli between long-day and shortday males. Each bar represents mean \pm SEM Z-scores to forward BOS, reverse BOS, and a conspecific song DC1 for long-day and short-day males. The forward BOS was most effective at driving HVC neurons in long-day males than in short-day ones. Asterisks indicate significant differences in paired or unpaired comparisons. $\boldsymbol{B}$, Results of experiment 2: comparisons of responses to song stimuli in short-day males. Each bar represents the mean \pm SEMZ-score. Five song stimuli were presented: the forward and reverse version of the BOS recorded under the short-day photoperiod (SD; filled bars), the forward and reverse version of the BOS recorded under the long-day photoperiod (LD, hatched bars), and the conspecific song DC1. Neurons in the HVC of short-day males did not respond differentially to any of these song stimuli.

$Z$-scores differed between song stimuli $\left(F_{(2,53)}=15.58 ; p<\right.$ $0.001)$, and paired-comparisons indicated that the mean $Z$-score to forward BOS was higher than that of the reverse BOS $\left(t_{(54)}=\right.$ $4.75 ; p<0.001)$ and that of the DC1 playback $\left(t_{(54)}=4.40 ; p<\right.$ $0.001)$. In contrast, in short-day males, $Z$-scores did not differ between song stimuli $\left(F_{(2,57)}<1\right.$; NS). Between-group comparison revealed that mean $Z$-score to forward BOS was larger in long-day than in short-day males $\left(t_{(113)}=3.5 ; p=0.007\right)$. To visualize this effect, $Z$-score to forward BOS was plotted against $Z$-score to reverse BOS (Fig. $5 A$ ). In long-day males, most of the cells ( 44 of $55,80 \%$ ) were above the diagonal line, indicating that their responses were stronger to forward than to reverse BOS. In contrast, in short-day males, only 25 of 59 cells (42\%) fired more to forward BOS than to reverse BOS. This change in the proportion of cells exhibiting higher firing rate to forward BOS was significant $\left(\chi^{2}=16.86 ; p<0.001\right)$. Similarly, when $Z$-score for forward BOS was plotted against $Z$-score for DC1 (Fig. $6 A$ ), the proportion of cells exhibiting a stronger increase in firing to forward BOS than to DC1 was larger in long-day than in short-day males ( 42 of 55 vs 29 of $59 ; \chi^{2}=8.97 ; p=0.003$ ).

Based on $Z$-scores, several results indicated that there was no overall change in auditory responsiveness. First, as mentioned above, a repeated ANOVA did not reveal an effect of the photoperiod factor, indicating that the $Z$-scores pooled over all stimuli did not differ between photoperiod conditions. Second, the number of cells exhibiting a positive $Z$-score to at least one song stimulus (i.e., with an evoked firing rate greater than the spontaneous rate) did not differ between long-day and short-day males (48 of 55 vs 51 of $59 ; \chi^{2}<1$; NS). Third, the distribution of $Z$-score values to the reverse BOS did not show a shift toward lower values of $Z$-score in short-day conditions (Fig. 5A). The percentage of cells with a positive $Z$-score value to the reverse BOS tended to be larger in short-day conditions (36 of 59, 61\%) than in long-day ones ( 24 of $55,44 \% ; \chi^{2}=3.10 ; p=0.08$ ). Last, analyzing responses to the song DC1 confirmed that the overall 
A. Experiment 1. Long-day vs. short-day males.
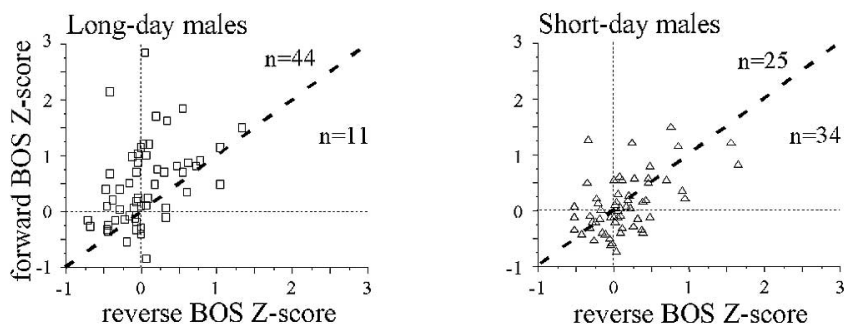

B. Experiment 2. Short-day males

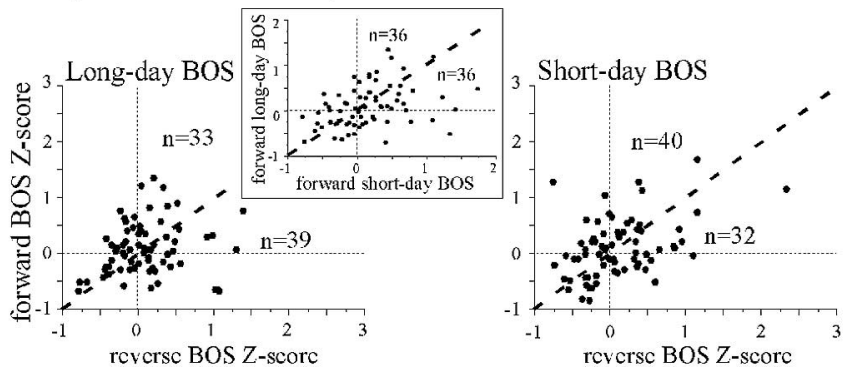

Figure 5. Response bias to forward BOS is only present in long-day birds. $A$, Results of experiment 1. Within-cell comparison of Z-score to forward BOS ( $y$-axis) is plotted against that for reverse BOS ( $x$-axis). The diagonal line represents equal responsiveness to forward and reverse BOS playbacks. In long-day males, most of the cells are above the diagonal line, indicating a bias to forward BOS. In contrast, there is no such bias in short-day males; there are even more cells below the diagonal line than above it. Note that the number of cells with a positive $Z$-score value to the reverse BOS was, respectively, 24 of 55 and 36 of 59 for the long-day and the short-day birds. $\boldsymbol{B}$, Results of experiment 2: no preference for any BOS in short-day males. Within-cell comparison of Z-score to forward BOS is plotted against that for reverse BOS. Note that as many cells are above the diagonal line as below it, for both the long-day and the short-day BOS. The inset shows the within-cell comparison of Z-score to forward short-day BOS against that for forward long-day BOS.

responsiveness remained similar in the 2-d-length conditions. The mean $Z$-score value to DC1 tended to be higher in short-day males than in long-day ones (Fig. $4 A$ ), although this effect did not reach significance $\left(t_{(130)}=1.41 ; p=0.15\right)$. The number of cells with a positive $Z$-score value to DC1 obtained in long-day and in short-day conditions was 26 of 55 (50\%) and 33 of 59 (56\%), respectively ( $\chi^{2}<1$; NS). In fact, as shown in Figure $6 A$, the highest $Z$-score values to the song DC1 (values between 1 and 2) were obtained for cells recorded in short-day males.

Selectivity to forward over reverse BOS was evaluated using the $d^{\prime}$ values. For this analysis, only cells with a positive $Z$-score to a song stimulus were considered (Fig. 7A). Mean $d^{\prime}$ forward-reverse Bos value was higher in males kept on long-day photoperiod than in males kept on short-day one $\left(0.54 \mathrm{vs}-0.02 ; t_{(98)}=3.9 ; p=\right.$ $0.005)$. The number of selective cells with a $d^{\prime}$ value $>1$ differed between the 2 -d-length conditions ( 12 of 48 vs 3 of $51 ; \chi^{2}=7.03$; $p=0.008)$. Selectivity to forward BOS over the conspecific song DC1 was also evaluated (Fig. $6 B$ ). Mean $d^{\prime}$ forward BOS-DC1 value was higher in long-day males than in short-day males (1.05 vs $\left.-0.06 ; t_{(98)}=2.6 ; p=0.012\right)$. The number of selective cells with a $d^{\prime}$ value $>1$ tended to be higher in long-day males than in short-day ones ( 14 of 48 vs 7 of $51 ; \chi^{2}=3.52 ; p=0.06$ ). If we restricted our analyses to cells showing significant auditory response to any song stimulus, a difference in selectivity was still observed: mean $d^{\prime}$ forward-reverse Bos value was higher in long-day males than in short-day males $\left(1.01\right.$ vs $0.46 ; t_{(34)}=2.13 ; p=$ 0.042 ). As shown in Table 2, a larger number of selective cells (i.e., cell with a $d^{\prime}$ value $>1$ ) was found in long-day than in short-day males ( 12 of 22 vs 2 of 13 cells; $\chi^{2}=5.22 ; p=0.02$ ). Exactly the same results were obtained when the $d^{\prime}$ values were computed for the DC1 song: the mean $d^{\prime}$ forward BOs-DC1 value was higher in long-day than in short-day males $\left(1.05\right.$ vs $-0.06 ; t_{(98)}=2.6 ; p=$ 0.012 ), and the number of selective cells was higher in long-day than in short-day males ( 12 of 22 vs 2 of $13 ; \chi^{2}=5.22 ; p=0.02$ ).

\section{Experiment 2: selectivity to a long-day and a short-day BOS in} short-day males

To assess whether HVC neurons of canaries housed on a shortday photoperiod retained selectivity for the well structured song produced during long-day photoperiod, 72 neurons from 10 short-day canaries were studied using both a current BOS and a BOS obtained when birds were on long days. The two BOS stimuli were played normally or time reversed; the same conspecific song DC1 was also used. Fifteen cells were recorded with tungsten electrodes; the remaining 57 cells were recorded with glass pipettes.

As in experiment 1 , the short-day BOS did not elicit a significant increase in firing rate above the spontaneous rate (2.2 vs 2.3 spike/s; $t_{(71)}<1$; NS). Likewise, playback of the forward long-day BOS was not efficient in increasing the mean firing rate (2.2 vs 2.1 spike/s; $\left.t_{(71)}=1.24 ; p=0.22\right)$. There was also no change in firing rate in response to the reverse version of the short-day BOS $(2.2$ vs 2.0 spike/s; $\left.t_{(71)}=1.11 ; p=0.26\right)$, the reverse version of the long-day BOS (2.2 vs 1.9 spike/s; $\left.t_{(71)}=1.71 ; p=0.09\right)$, and conspecific song DC1 (2.1 vs 2.0 spike/s; $\left.t_{(54)}=1.26 ; p=0.21\right)$.

Individually, eight cells (11\%) exhibited a significant increase in firing rate during the short-day BOS playback (see an example in Fig. 8), and six cells (8\%) exhibited a significant response to its reverse version. Exactly the same results were obtained for the long-day BOS: eight cells (11\%) exhibited a significant increase in firing rate during long-day BOS playback, and six cells (8\%) exhibited a significant response to its reverse version. Of these cells, only one responded to both long-day and short-day BOS playbacks. Ten cells (14\%) responded significantly to the DC1 playback. Overall, a total of 28 cells (39\%) exhibited auditory responses to at least one of the five song stimuli; among them, four responded to two song stimuli, and three responded to three song stimuli.

The population of neurons recorded in short-day canaries did not respond differentially to any of the stimuli, as indicated by a repeated ANOVA on $Z$-scores (song and photoperiod as factors; $F_{(2,71)}<1$; NS in the two cases) (Fig. $4 B$ ). No preference was observed from the scatter grams of the $Z$-score for forward BOS plotted against that of reverse BOS (Fig. 5B). Using the long-day BOS, 33 cells ( $46 \%$ ) were above and 39 cells (54\%) were below the diagonal line; using short-day BOS, 40 cells (56\%) were above and $32(44 \%)$ were below the diagonal line. These proportions did not differ between long-day BOS and short-day BOS $\left(\chi^{2}=\right.$ 1.36; $p=0.24)$. More importantly, when $Z$-score of forward long-day BOS was plotted against that of short-day BOS, an equal number of cells $(n=36)$ was found on each side of the diagonal line (Fig. $5 B$, inset). Thus, on average, the population of HVC neurons recorded in short-day canaries did not exhibit preference for any BOS. Using only the cells exhibiting a positive $Z$-score value to at least one song stimulus, the distributions of $d^{\prime}$ forward-reverse Bos values confirmed that the selectivity did not differ between long-day BOS and short-day BOS (Fig. 7B). The mean $d^{\prime}$ values did not differ between long-day BOS and short-day BOS $\left(0.12\right.$ vs $\left.0.11 ; t_{(61)}<1\right)$, and an equal number of selective cells $\left(d^{\prime}\right.$ value $>1$ ) was found for the two types of BOS (6 of 62). Restricting the analyses to the cells that exhibited significant auditory 
A.

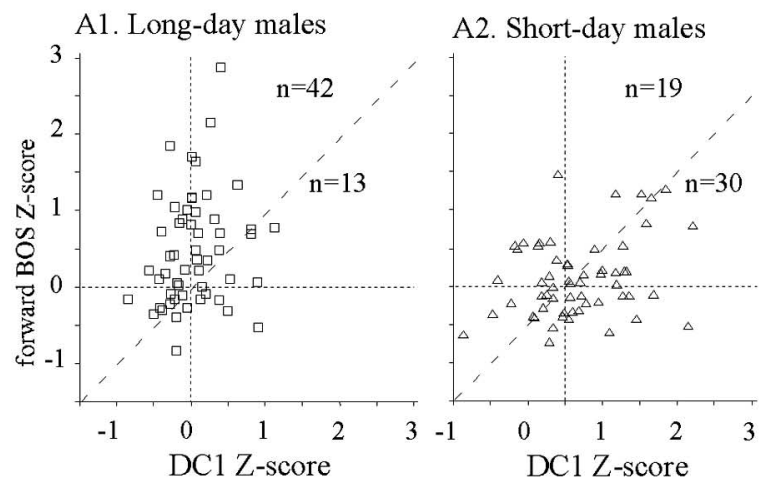

B.

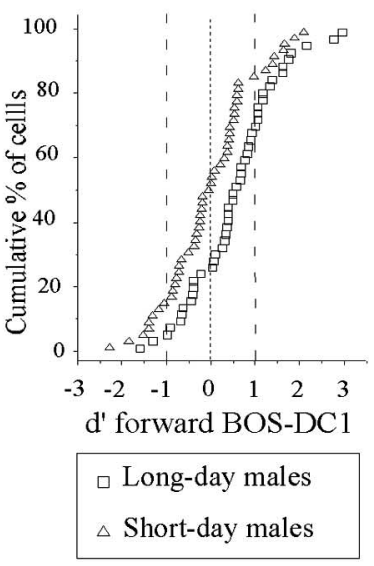

Figure 6. Differences in song selectivity to the forward BOS over the conspecific song (DC1) between long-day and short-day males. $A$, Within-cell comparison of Z-score to forward BOS ( $y$-axis) is plotted against that for conspecific song DC1 ( $x$-axis). The diagonal line represents equal responsiveness to forward BOS and DC1 playbacks. In long-day males (A1), most of the cells are above the diagonal line, indicating a bias to forward BOS. In contrast, there is no such bias in short-day males (A2); there are even more cells below the diagonal line than above it. Note that the highest Z-score values to the song DC1 were obtained for cells recorded in short-day males. $\boldsymbol{B}$, Song selectivity was also described in terms the distribution of $d^{\prime}$ values for HVC single units. For the $d^{\prime}{ }_{\text {forward BoS-DC1 }}$ measure, the more positive is the $d^{\prime}$ value, the more song-selective is the response of the neuron; $a d^{\prime}$ value $>1$ was used as the criterion for identifying a cell as selective. The cumulative distribution of $d^{\prime}$ values is displayed for the cells recorded in long-day males (open squares) and for cells recorded in short-day ones (open triangles). Only cells with a positive $Z$-score to at least one song stimulus were considered.

\section{A. Experiment 1}

Long-day vs. short-day males

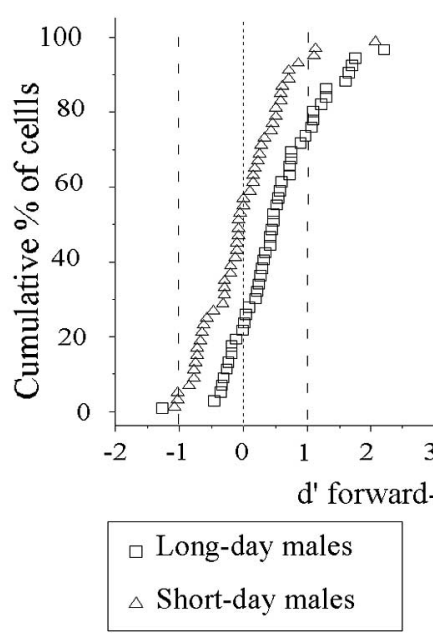

B. Experiment 2 Short-day males

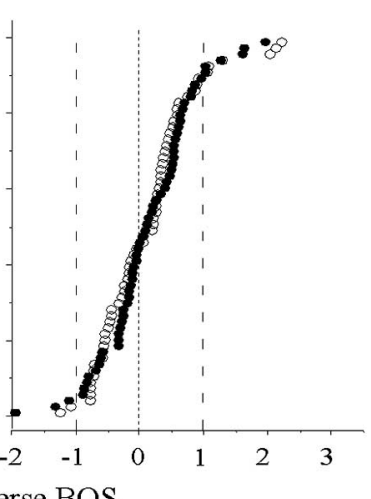

- Long-day BOS

- Short-day BOS

Figure 7. Differences in song selectivity to forward over reverse BOS between long-day and short-day males. $\boldsymbol{A}$, Results of experiment 1: the cumulative distribution of $d^{\prime}{ }_{\text {forward-reverse BOS }}$ values is displayed for the cells recorded in long-day males (open squares) and for cells recorded in short-day ones (open triangles) that obtained a positive Z-score to at least one song stimulus. The number of selective neurons $\left(d^{\prime}>1\right)$ was greater in long-day males than in short-day ones. $B$, Results of experiment 2: the cumulative distributions of $d^{\prime}$ values showed that the degree of selectivity did not differ between long-day songs (forward vs reverse long-day BOS; open circles) and short-day songs (forward vs reverse short-day BOS; filled circles). The number of selective neurons $\left(d^{\prime}>1\right)$ was low regardless of the BOS considered. Only cells with a positive $Z$-score to at least one song stimulus were considered.

responses gave the same results: there were no differences between the long-day BOS and the short-day BOS in terms of mean $d^{\prime}$ values $\left(0.19\right.$ vs $\left.0.11 ; t_{(27)}<1\right)$ and in terms of number of selective cells ( $d^{\prime}$ value $>1 ; 4$ of 28 for each BOS).

\section{Song selectivity of putative HVC cell types}

Several characteristics such as spike width and rate of spontaneous activity allowed us to distinguish between putative relay cells and putative interneurons within HVC nucleus. Interneurons are characterized by narrow action potentials and a high rate of spontaneous activity, whereas neurons projecting either to area $\mathrm{X}$ or to the robust nucleus of the arcopallium (Reiner et al., 2004) have broader action potentials and a lower rate of spontaneous firing (Mooney, 2000; Rauske et al., 2003). Because studies reported that relay cells and interneurons exhibit different auditory responses (phasic vs tonic) to song stimuli (Mooney, 2000, Mooney et al., 2001), it was of importance to collect a similar proportion of thin spike cells in long-day males and in short-day males in both experiments. This was indeed the case: thin spike cells represented $20 \%$ (11 of 55) and 15\% (9 of 59) of cells recorded in long-day and in short-day males, respectively, in experiment 1 . They represented $20 \%$ ( 15 of 72 ) of cells recorded in experiment 2.

As shown in Figure 9A, cells with thin action potentials $(<0.4 \mathrm{~ms} ; n=35)$ differed from cells with broad ones ( $\geq 0.45 \mathrm{~ms} ; n=151)$ by their higher spontaneous activity ( 3.0 vs $\left.1.52 \mathrm{~Hz} ; t_{(184)}=3.75 ; p<0.001\right)$. The mean recording depth of thin spike cells did not differ from that of broad spike cells (range, $200-800 \mu \mathrm{m} ; 504$ vs $529 \mu \mathrm{m} ; t<1$; NS). For thin spike cells, spontaneous activity did not differ between long-day ( $n=11$ cells) and short-day ( $n=24$ cells) conditions ( 3.32 vs $2.88 \mathrm{~Hz} ; t_{(33)}<1$; NS). In contrast, broad spike cells exhibited a higher spontaneous rate in long-day ( $n=44$ cells) than in shortday $(n=107$ cells $)$ conditions ( 1.84 vs $1.12 \mathrm{~Hz} ; t_{(149)}=2.02 ; p=$ $0.04)$. For the subsequent analyses, responses to the short-day BOS obtained in experiments 1 and 2 were pooled together.

In long-day males, 7 of 11 (64\%) thin spike cells and 15 of 44 (34\%) broad spike cells showed a significant auditory response to, at least, one song stimulus. In short-day males, 11 of 24 (46\%) thin spike cells and 30 of 107 (28\%) broad spike cells exhibited such a response. For both cell types, photoperiod conditions did not affect the proportion of auditory responsive cells $\left(\chi^{2}<1\right.$ in both cell types). Overall, there was a larger number of auditory responsive cells among thin spike cells than among broad spike cells ( 18 of 35 vs 45 of $151 ; \chi^{2}=5.93 ; p=0.015$ ).

The repeated ANOVA on $Z$-scores of thin spike cells indicated a significant effect of song factor, i.e., differential responses to forward and reverse $\operatorname{BOS}\left(F_{(1,33)}=24.66 ; p<0.001\right)$ and an interaction between the effects of songs and those of photoperiod conditions $\left(F_{(1,33)}=10.51 ; p=0.003\right)$. For broad spike cells, exactly the same results were obtained: a significant effect of song factor $\left(F_{(1,149)}=8.65 ; p=0.0038\right)$ and an interaction between the two factors $\left(F_{(1,149)}=13.87 ; p<0.001\right)$. On average (Fig. 9B), both cell types responded significantly more to forward than to reverse BOS in long-day males (thin spike cells, $t_{(10)}=3.52, p=$ 0.005 ; broad spike cells, $\left.t_{(43)}=3.69, p=0.006\right)$. These differences were not observed in short-day males (thin spike cells, $t_{(23)}=$ $1.89, p=0.07$; broad spike cells, $t_{(106)}<1$, NS). In addition, 

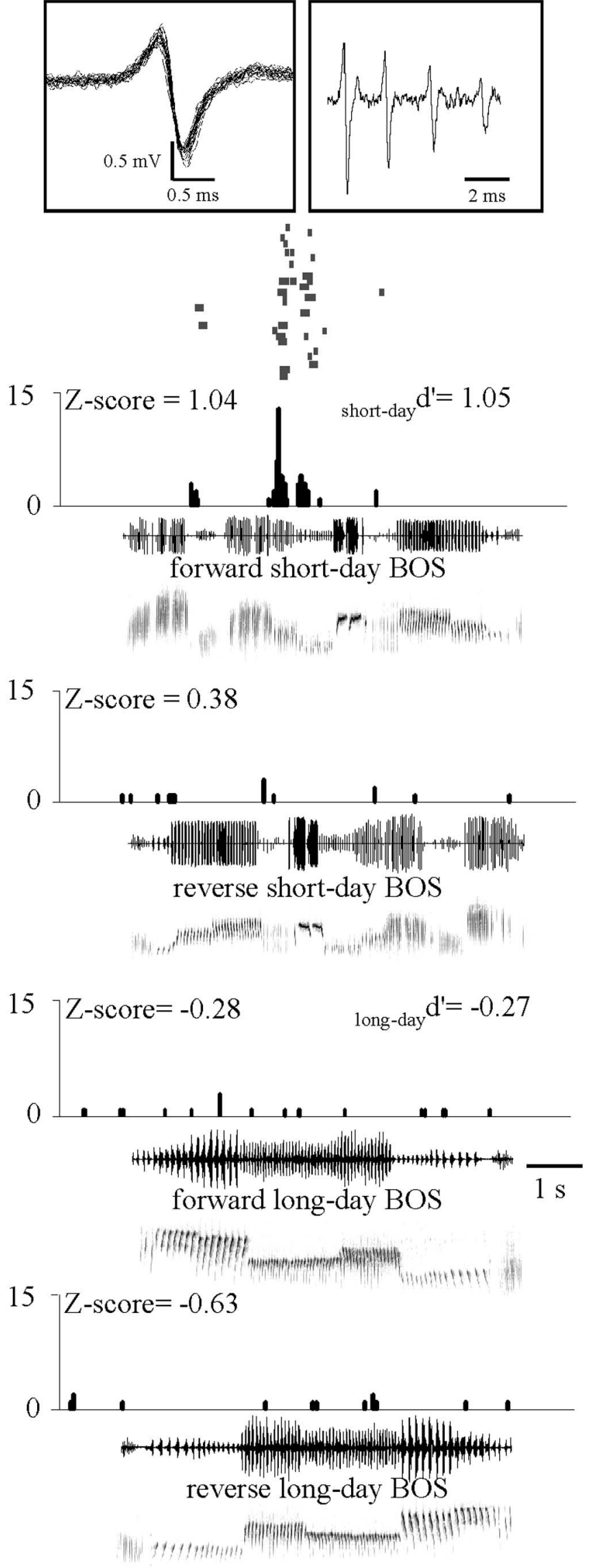

$Z$-scores to forward BOS differed between long-day and shortday males (thin spike cells, $t_{(33)}=3.60, p=0.001$; broad spike cells, $\left.t_{(149)}=3.58, p<0.001\right)$. For cells exhibiting a positive $Z$-score value to at least one song stimulus, mean $d^{\prime}$ forward-reverse Bos value differed between long-day and short-day males (thin spike cells, 1.16 vs $0.32, t_{(26)}=2.67, p=0.01$; broad spike cells, 0.40 vs $0.01, t_{(131)}=3.08, p=0.002$ ). The number of selective $\left(d^{\prime}>1\right)$ thin spike cells was higher in long-day than in short-day conditions ( 6 of 9 vs 4 of $19 ; \chi^{2}=5.53 ; p=0.018$ ); the number of selective broad spike cells tended to be higher in long-day than in short-day conditions ( 6 of 39 vs 5 of $94 ; \chi^{2}=3.68 ; p=0.055$ ). Exactly the same results were obtained when the analyses were restricted to cells exhibiting significant auditory responses: mean $d^{\prime}$ forward-reverse Bos value was higher in long-day males than in short-day males (thin spike cells, 1.36 vs $0.35 ; t_{(16)}=1.02, p=$ 0.002 ; broad spike cells, 0.73 vs $0.20, t_{(43)}=2.15, p=0.038$ ), and a larger number of selective cells was found in long-day than in short-day males (thin spike cells, 5 of 7 vs 2 of $11, \chi^{2}=5.10, p=$ 0.02 ; broad spike cells, 7 of 15 vs 4 of $30, \chi^{2}=6.01, p=0.01$ ). Thus, the selectivity of both cell types was affected by photoperiodic conditions.

Last, responses to the song DC1 obtained from short-day males in the two experiments were pooled together. Whatever the cell type, $Z$-scores to the conspecific song DC1 did not differ between long-day and short-day males (thin spike cells, 0.08 vs 0.16 ; broad spike cells, 0.01 vs 0.08 ; all $p$ values $>0.61$ ).

\section{Discussion}

Sampling neurons in the HVC of canaries kept in long-day and in short-day conditions (experiment 1) revealed striking differences. Whereas 35\% of the cells recorded in long-day conditions presented a significant increase in firing rate at BOS presentation, only $12 \%$ of the cells recorded in short-days conditions did. The mean $Z$-scores significantly differed between the forward BOS and the reverse BOS (and the conspecific song) in long-day conditions, whereas it was not the case in short-day conditions. There were four times more selective cells $\left(d^{\prime}\right.$ index $\left.>1\right)$ for the current BOS over its reversed version in long-day than in short-day conditions. Testing the HVC neurons of canaries kept on short-days conditions with a long-day BOS and a short-day BOS (experiment 2) fully confirmed these effects. Significant responses to the long-day or to the short-day BOS were observed for only $11 \%$ of the cells (and only one cell responded to both BOS). The number of selective neurons $\left(d^{\prime}>1\right)$ was low for both the short-day and the long-day BOS. These data demonstrate that the proportion of HVC neurons selective for the BOS was strongly reduced by short-day conditions, mimicking those of the nonbreeding season. This decrease in the proportion of selective cells affected both broad spike cells (putative relay cells) and thin spike cells (putative local interneurons). Before considering the potential

Figure 8. Example of a song-selective HVC neuron in short-day males. During playback of forward short-day BOS, this cell exhibited a phasic increase in activity. In contrast, playbacks of the other song stimuli elicited no change in firing rate. This neuron displayed a broad action potential (duration, $0.8 \mathrm{~ms}$ ). Insets show its action potential waveform ( 30 sweeps, $50 \mathrm{kHz}$ sampling rate) and an example of a raw trace ( $50 \mathrm{kHz}$ sampling rate). Histograms display the number of action potential per bins of $25 \mathrm{~ms}$ and are accompanied by raster plots for forward short-day BOS responses. Oscillograms and sonograms of songs are below histograms. The $Z$-score values are indicated above histograms. The $d^{\prime}$ value for forward versus reverse long-day BOS (long-day $d^{\prime}$ ) and that for forward versus reverse short-day BOS ( short-day $d^{\prime}$ ) are indicated. Thirty trials of each stimulus were presented, but the $Z$-scores and $d^{\prime}$ values used in group analyses were calculated from responses to the first 10 presentations of song stimuli. 
A

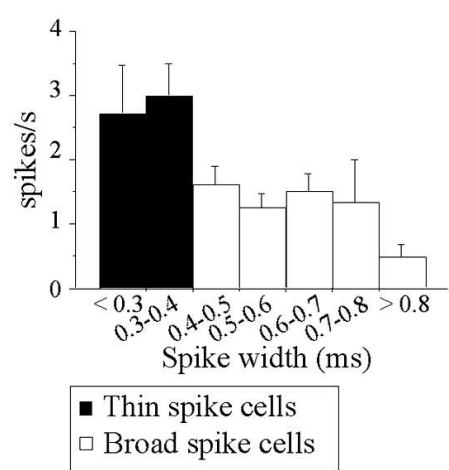

B

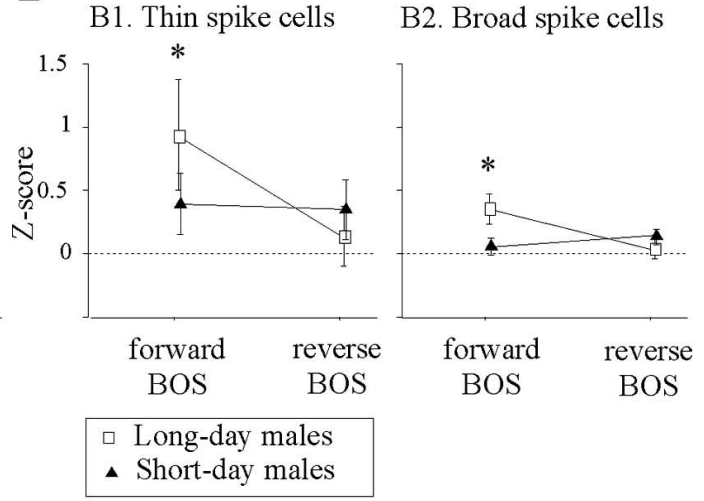

Figure 9. Day-length conditions affected response bias to forward BOS in both cell types. $A$, Relationships between spike width and rate of spontaneous activity distinguished two cell types. Cells with thin action potentials ( $<0.4 \mathrm{~ms} ; n=35$; thin spike cells) exhibited a higher spontaneous activity than cells with broader action potentials ( $\geq 0.45 \mathrm{~ms} ; n=151$; broad spike cells). $\boldsymbol{B}$, Mean \pm SEM Z-scores to playbacks of forward and reverse BOS were compared between long-day and short-day males for thin spike (B1) and broad spike (B2) cells. Both cell types responded significantly more to forward than to reverse BOS in long-day males $(p<0.005)$. No difference was observed in short-day males, regardless of the cell type considered.

mechanisms and functional implications of these results, a few methodological points should be discussed.

\section{Methodological considerations \\ Photoperiod conditions}

In the present study, the duration of the photoperiod was manipulated to mimic the breeding and nonbreeding conditions. These photoperiod manipulations were efficient to trigger reproductive behavior in both male and female canaries in laboratory conditions (Storey and Nicholls, 1976; Appeltants et al., 2001; Parisot et al., 2002) and had, here, a drastic impact on the size and weight of testis. One can argue that unknown is the consequence of this treatment on the testosterone level and that testis weight is not directly correlated with testosterone levels. However, whatever the exact level of testosterone in short-day males, all birds displayed striking alterations of their song when placed in short-day conditions. This indicates that manipulations of photoperiod indeed had physiological and behavioral consequences. Furthermore, if manipulations of photoperiod in laboratory conditions had little impact on testosterone level (Kirn and Schwabl, 1997), this suggests that testosterone level is not directly responsible for changes in neuronal selectivity in male HVC.

\section{Selection of BOS}

Unlike the species commonly used in electrophysiological studies, the zebra finch and the white crowned sparrow, which both vocalize a single song (Margoliash, 1983, 1986; Lewicki, 1996; Theunissen and Doupe, 1998; Mooney, 2000), male canaries produce complex songs. On average, the canary syllable repertoire contains $\sim 25$ syllables, and only a part of this repertoire $(8-10$ syllables) is present in each song. Special care was taken to select the song containing the syllables, and the sequences of syllables, detected most often in each bird repertoire. This meticulous selection of the BOS was probably a key element to detect a percentage of cells responsive to BOS presentation (19 of 55, 35\%) similar to those found in other extracellular single-unit studies in zebra finches (Margoliash and Fortune, 1992; Lewicki and Arthur, 1996). Obviously, one can argue that cells classified here as nonresponsive for the selected long-day BOS could be sensitive to features present in less frequent, nonpresented syllables, as suggested by two recent studies (Mooney et al., 2001; Nealen and Schmidt, 2002). This raises fundamental questions about the as- pects of acoustic stimuli, which allow HVC neurons to display strong preference for the BOS in a songbird species. However, in no way does this unresolved issue invalidate our finding: the song selected as short-day BOS was as representative of a given bird as the long-day BOS was and, still, differences in selectivity were detected.

\section{Potential mechanisms underlying changes in BOS selectivity}

Based on the results of experiment 2, the possibility that the reduced proportion of selective neurons in canaries exposed to short-days was attributable to nonoptimal acoustic characteristics of the unstable short-day BOS can be ruled out. Only a few neurons recorded in nonbreeding conditions exhibited selectivity for the highly stereotyped long-day BOS, and the proportion of selective cells for the stereotyped long-day BOS was similar to that obtained for the unstable short-day BOS. The reduced proportion of selective cells in short-day conditions resulted from two factors. First, playback of the BOS was less efficient in triggering neuronal responses in nonbreeding males than in breeding ones, as indicated by the number of cells showing significant responses to playback of the forward BOS (in long-day males, 19 of 55 cells; in short-day males, 7 of 59 and 16 of 72 cells in experiments 1 and 2, respectively). Second, the number of cells that responded only to playback of the forward BOS was lower in nonbreeding males than in breeding ones. Therefore, this suggests that long-day conditions not only increased the level of auditory responsiveness but also promoted the emergence of neurons responding exclusively to the BOS.

Before evaluating the potential mechanisms underlying changes in neuronal selectivity, it is necessary to consider what are the current hypotheses proposed for the presence of selective neurons within HVC. Extracellular recordings suggested that the selectivity for BOS is higher in HVC than in its auditory afferents (Lewicki and Arthur, 1996; Janata and Margoliash, 1999). In vivo intracellular recordings revealed that HVC neurons often exhibited subthreshold responses to stimuli (e.g., reverse BOS) that failed to evoke action potentials (Mooney, 2000; Mooney et al., 2001). In fact, a recent study indicated (1) that a high selectivity for the BOS first arose in the interfacial nucleus of the nidopallium (NIf) and (2) that HVC neurons transformed excitatory inputs from NIf, occurring during all song stimuli, into BOS exclusive action potential responses, emphasizing the selectivity for the BOS (Coleman and Mooney, 2004). Potentially, these results indicated that local inhibitory mechanisms play an important role in promoting the selectivity of HVC neurons. However, this view does not agree with data obtained by blocking inhibitions during intracellular recordings of X-projecting cells: GIRK (G-protein-gated inwardly rectifying $\mathrm{K}^{+}$channel) mediatedinhibition rather acts to suppress the suprathreshold response bias to the forward BOS rather than to actively enhance it (Rosen and Mooney, 2003). However, we should consider that, instead of acting via simple thresholding, inhibition might shape neuronal selectivity by complex temporal patterns, i.e., by transient membrane hyperpolarization, that allow precise burst firing.

Various mechanisms may modulate functional properties of 
the different HVC cell types when switching from breeding to nonbreeding conditions. For example, neurons of canary HVC express androgen and estrogen receptors (Gahr et al., 1987; Gahr, 1990; Metzdorf et al., 1999) and are sensitive to fluctuations in hormonal level (Fusani et al., 2000). Through changes in the morphology of the neurons (Rasika et al., 1994, 1999) as well as changes in synaptic connections between cells (Gahr and GarciaSegura, 1996), steroid hormones might be potent regulators of physiological and functional properties of HVC neurons. Hormonal levels can also regulate catecholamine innervations of most song control nuclei (Appeltants et al., 2003; Ball et al., 2003) and, as a consequence, affect the functional connectivity within and between structures (Wong and Moss, 1992; Murphy et al., 1998; Rudick and Woolley, 2001; Van Meir et al., 2004). Last, neurogenesis might play a role in this change in neuronal selectivity. Late summer, period of song instability, and low testosterone level correspond to the greatest new HVC neuron incorporation (Kirn et al., 1994; Alvarez-Buylla and Kirn, 1997; Nottebohm, 2002). One can envision that the increased neuronal death and increased neuron recruitment disorganize the HVC network and prevent neurons to be tuned to the song produced in short-day conditions. Although the lack of selectivity of HVC neurons recorded in nonbreeding birds might derive from seasonal-driven changes intrinsic to the HVC nucleus, we should not exclude the possibility that this effect derives, at least in part, from the modulation of HVC afferents (potentially from NIf).

\section{Functional interpretations and conclusions}

At least three outcomes could have been predicted at the beginning of our experiment. An initial prediction was that HVC cells are always selective for the current BOS, even outside the breeding season. This prediction supposes that the tuning of HVC neurons is continuously adapted to the current song and is controlled by the pattern of neuronal activity expressed while singing at any given time period. This could be envisioned because the HVC nucleus has long been considered as a site in which auditory and motor activity are combined (Nottebohm et al., 1976; McCasland and Konishi, 1981; Vu et al., 1994; Yu and Margoliash, 1996), and recent studies clearly indicated that, besides their auditory selectivity for the BOS, HVC neurons exhibit singingrelated premotor patterns of activity (Yu and Margoliash, 1996; Hahnloser et al., 2002). That HVC neurons in juvenile birds develop selectivity for the bird's own vocalizations in parallel with the development of vocal learning (Volman, 1993) is also in agreement with this view. A second potential outcome was that the selectivity of HVC neurons for the BOS of the breeding season persists outside this period despite the fact that the bird modifies its song. According to this prediction, the maintenance of this selectivity could be viewed as a memory trace of the previous BOS. The results obtained here invalidate these two predictions. They favor a third outcome: in the short-day photoperiod (mimicking the nonbreeding conditions), HVC cells became less selective to the BOS (the one sung in long-day and the one sung in short-day conditions). This indicates that singing is not sufficient to promote selective cells in HVC. Rather, our data suggest that singing a more stereotyped song at the breeding season impacts on the neuronal selectivity of HVC cells and leads to a response bias in favor of the bird's own song. Altogether, the present results pointed out that the selectivity of HVC neurons for the BOS is not a fixed property: it can move among a continuum when the photoperiod conditions change. Deciphering the mechanisms of this remarkable model of plasticity is now an important challenge for future research.

\section{References}

Alvarez-Buylla A, Kirn JR (1997) Birth, migration, incorporation and death of vocal control neurons in adult songbirds. J Neurobiol 33:585-601.

Appeltants D, Ball GF, Balthazart J (2001) The distribution of the tyrosine hydroxylase in the canary brain: demonstration of a specific and sexually dimorphic catecholaminergic innervation of the telencephalic song control nuclei. Cell Tissue Res 304:237-259.

Appeltants D, Ball GF, Balthazart J (2003) Song activation by testosterone is associated with an increased catacholaminergic innervation of the song control system in female canaries. Neuroscience 121:801-814.

Ball GF, Castelino CB, Maney DL, Appeltants D, Balthazart J (2003) The activation of birdsong by testosterone: multiple sites of action and role of ascending catecholamine projections. Ann NY Acad Sci 1007:211-231.

Cardin JA, Schmidt MF (2003) Song system auditory responses are stable and highly tuned during sedation, rapidly modulated and unselective during wakefulness, and suppressed by arousal. J Neurophysiol 91:2148-2163.

Coleman MJ, Mooney R (2004) Synaptic transformations underlying highly selective auditory representation of learned birdsong. J Neurosci 18:9251-9265.

Del Negro C, Edeline JM (2001) Differences in auditory and physiological properties of HVc neurons between reproductively active male and female canaries (Serinus canaria). Eur J Neurosci 14:1377-1389.

Del Negro C, Edeline JM (2002) Sex and season influence the proportion of thin spike cells in the canary HVc. NeuroReport 13:2005-2009.

DeVoogd TJ, Nottebohm F (1981) Gonadal hormones induce dendritic growth in the adult avian brain. Science 214:202-204.

DeVoogd TJ, Nixdorf B, Nottebohm F (1985) Synaptogenesis and changes in synaptic morphology related to acquisition of a new behavior. Brain Res 329:304-308.

Fusani L, Van't Hof T, Hutchinson JB, Gahr M (2000) Seasonal expression of androgen receptors, estrogen receptors and aromatase in the canary brain in relation to circulating androgens and estrogens. J Neurobiol 43:254-268.

Gahr M (1990) Localization of androgen receptors and estrogen receptors in the same cells of the songbird brain. Proc Natl Acad Sci USA 87:9445-9448.

Gahr M, Garcia-Segura LM (1996) Testosterone-dependent increase of gap-junctions in $\mathrm{HVc}$ neurons of adult female canaries. Brain Res 712:69-73.

Gahr M, Flügge G, Güttinger HR (1987) Immunocytochemical localization of estrogen-binding neurons in the songbird brain. Brain Res 402:173-177.

Green D, Swets J (1966) Signal detection theory and psychophysics. New York: Wiley.

Gur M, Beylin A, Snodderly DM (1999) Physiological properties of macaque V1 neurons are correlated with extracellular spike amplitude, duration and polarity. J Neurophysiol 82:1451-1464.

Güttinger HR (1985) Consequences of domestication on the song structure in the canary. Behaviour 94:254-278.

Hahnloser HR, Kozhevnikov AA, Fee MS (2002) An ultra-sparse code underlies the generation of neural sequences in a songbird. Nature 419:65-70.

Henze DA, Borhegyi Z, Csicsvari J, Mamiya A, Harris KD, Buzsaki G (2000) Intracellular features predicted by extracellular recordings in the hippocampus in vivo. J Neurophysiol 84:390-400.

Hill KM, DeVoogd TJ (1991) Altered day length affects dendritic structure in a song-related brain region in red-winged blackbirds. Behav Neural Biol 56:240-250.

Huetz C, Lebas N, Del Negro C, Lehongre K, Tarroux P, Edeline JM (2004) Do HVC neurons use a temporal code to represent the bird's own song (BOS)? Soc Neurosci Abstr 30:333.2.

Kirn JR, Schwabl H (1997) Photoperiod regulation of neuron death in the adult canary. J Neurobiol 33:223-231.

Kirn JR, O’Loughlin B, Kasparian S, Nottebohm F (1994) Cell death and neuronal recruitment in the high vocal center of adult male canaries are temporally related to changes in song. Proc Natl Acad Sci USA 91:7844-7848.

Janata P, Margoliash D (1999) Gradual emergence of song selectivity in sensorimotor structures of the male zebra finch song system. J Neurosci 19:5108-5118.

Leitner S, Voigt C, Gahr M (2001) Seasonal changes in the song pattern of 
the non-domesticated island canary (Serinus canaria), a field study. Behaviour 138:885-904.

Lewicki MS (1996) Intracellular characterization of song-specific neurons in the zebra finch auditory forebrain. J Neurosci 15:5854-5863.

Lewicki MS, Arthur BJ (1996) Hierarchical organization of auditory temporal context sensitivity. J Neurosci 16:6987-6998.

Lewicki MS, Konishi M (1995) Mechanisms underlying the sensitivity of songbird forebrain neurons to temporal order. Proc Natl Acad Sci USA 92:5582-5586.

Margoliash D (1983) Acoustic parameters underlying the response of songspecific neurons in white-crowned sparrows. J Neurosci 3:1039-1057.

Margoliash D (1986) Preference for autogenous song by auditory neurons in a song system nucleus of the white-crowned sparrow. J Neurosci 6:1643-1661.

Margoliash D, Fortune ES (1992) Temporal and harmonic combination sensitive neurons in the zebra finch's HVc. J Neurosci 12:4309-4326.

McCasland JS, Konishi M (1981) Interaction between auditory and motor activities in an avian song control nucleus. Proc Natl Acad Sci USA 12:7815-7819.

Metzdorf R, Gahr M, Fusani L (1999) Distribution of aromatase, estrogen receptor, and androgen receptor mRNA in the forebrain of songbirds and nonsongbirds. J Comp Neurol 407:115-129.

Mooney R (2000) Different subthreshold mechanisms underlie song selectivity in identified $\mathrm{HVc}$ neurons of the zebra finch. J Neurosci 20:5420-5436.

Mooney R, Hoese W, Nowicki S (2001) Auditory representation of the vocal repertoire in a songbird with multiple song types. Proc Natl Acad Sci USA 98:12778-12783.

Murphy DD, Cole NB, Greenberger V, Segal M (1998) Estradiol increases dendritic spine density by reducing GABA neurotransmission in hippocampal neurons. J Neurosci 18:2550-2559.

Nagle L, Kreutzer M (1997) Song tutoring influences female song preferences in domesticated canaries. Behaviour 134:89-104.

Nealen PN, Schmidt ME (2002) Comparative approaches to avian song system function: insights into auditory and motor processing. J Comp Physiol [A] 188:929-941.

Nick TA, Konishi M (2001) Dynamic control of auditory activity during sleep: correlation between song response and EEG. Proc Natl Acad Sci USA 98:14012-14016.

Nottebohm F (1981) A brain for all seasons: cyclical anatomical changes in song control nuclei of the canary brain. Science 214:1368-1370.

Nottebohm F (2002) Why are some neurons replaced in adult brain? J Neurosci 22:624-628.

Nottebohm F, Stokes TM, Leonard CM (1976) Central control of song in the canary, Serinus canarius. J Comp Neurol 165:457-486.

Nottebohm F, Nottebohm ME, Crane LA (1986) Developmental and seasonal changes in canary song and their relation to changes in the anatomy of song-control nuclei. Behav Neural Biol 46:445-471.

Nottebohm F, Nottebohm ME, Crane LA, Wingfield JC (1987) Seasonal changes in gonadal hormone levels of adult male canaries and their relation to song. Behav Neural Biol 47:197-211.

Parisot M, Vallet E, Nagle L, Kreutzer M (2002) Male canaries discriminate among song: call rate is a reliable measure. Behaviour 139:55-63.
Rasika S, Nottebohm F, Alvarez-Buylla A (1994) Testosterone increases the recruitment and/or survival of new high vocal center neurons in adult female canaries. Proc Natl Acad Sci USA 91:7854-7858.

Rasika S, Alvarez-Buylla A, Nottebohm F (1999) BDNF mediates the effects of testosterone on the survival of new neurons in an adult brain. Neuron 22:53-62.

Rauske PL, Shea SD, Margoliash D (2003) State and neural class-dependent reconfiguration in the avian song system. J Neurophysiol 89:1688-1703.

Reiner A, Perkel DJ, Bruce LL, Butler AB, Csillag A, Kuenzel W, Medina L, Paxinos G, Shimizu T, Striedter G, Wild M, Ball GF, Durand S, Gunturkun O, Lee DW, Mello CV, Powers A, White SA, Hough G, Kubikova L, et al. (2004) Revised nomenclature for avian telencephalon and some related brainstem nuclei. J Comp Neurol 473:377-414.

Rosen MJ, Mooney R (2003) Inhibitory and excitatory mechanisms underlying auditory responses to learned vocalizations in the songbird nucleus HVC. Neuron 39:177-194.

Rudick CN, Woolley CS (2001) Estrogen regulates functional inhibition of hippocampal CA1 pyramidal cells in the adult female rat. J Neurosci 21:6532-6543.

Solis MM, Doupe AJ (1997) Anterior forebrain neurons develop selectivity by an intermediate stage of birdsong learning. J Neurosci 17:6447-6462.

Stokes TM, Leonard CM, Nottebohm F (1974) The telencephalon, diencephalon, and mesencephalon of the canary, Serinus canaria, in stereotaxic coordinates. J Comp Neurol 156:337-374.

Storey CR, Nicholls TJ (1976) Some effects of a manipulation of daily photoperiod on the rate of onset of a photorefractory state in canaries (Serinus canarius). Gen Comp Endocrinol 30:204-208.

Theunissen FE, Doupe AJ (1998) Temporal and spectral sensitivity of complex auditory neurons in the nucleus $\mathrm{HVc}$ of male zebra finches. J Neurosci 18:3786-3802.

Tramontin AD, Brenowitz EA (2000) Seasonal plasticity in the adult brain. Trends Neurosci 23:251-258.

Vallet E, Kreutzer M (1995) Female canaries are sexually responsive to special song phrases. Anim Behav 49:1603-1610.

Van Meir V, Verhoye M, Absil P, Eens M, Balthazart J, Van der Linden A (2004) Differential effects of testosterone on neuronal populations and their connections in a sensorimotor brain nucleus controlling song production in songbirds: a manganese enhanced-magnetic resonance imaging study. NeuroImage 21:914-923.

Volman SF (1993) Development of neural selectivity for birdsong during vocal learning. J Neurosci 13:4737-4747.

Vu ET, Mazurek ME, Kuo YC (1994) Identification of a forebrain motor programming network for the learned song of zebra finches. J Neurosci 14:6924-6934.

Wilson FA, Scalaidhe SPO, Goldman-Rakic PS (1994) Functional synergism between putative $\gamma$-amino-butyrate-containing neurons and pyramidal neurons in prefrontal cortex. Proc Natl Acad Sci USA 91:4009-4013.

Wong M, Moss RL (1992) Long-term and short-term electrophysiological effects of estrogen on the synaptic properties of hippocampal CA1 neurons. J Neurosci 12:3217-3225.

Yu AC, Margoliash D (1996) Temporal hierarchical control of singing in birds. Science 273:1871-1875. 